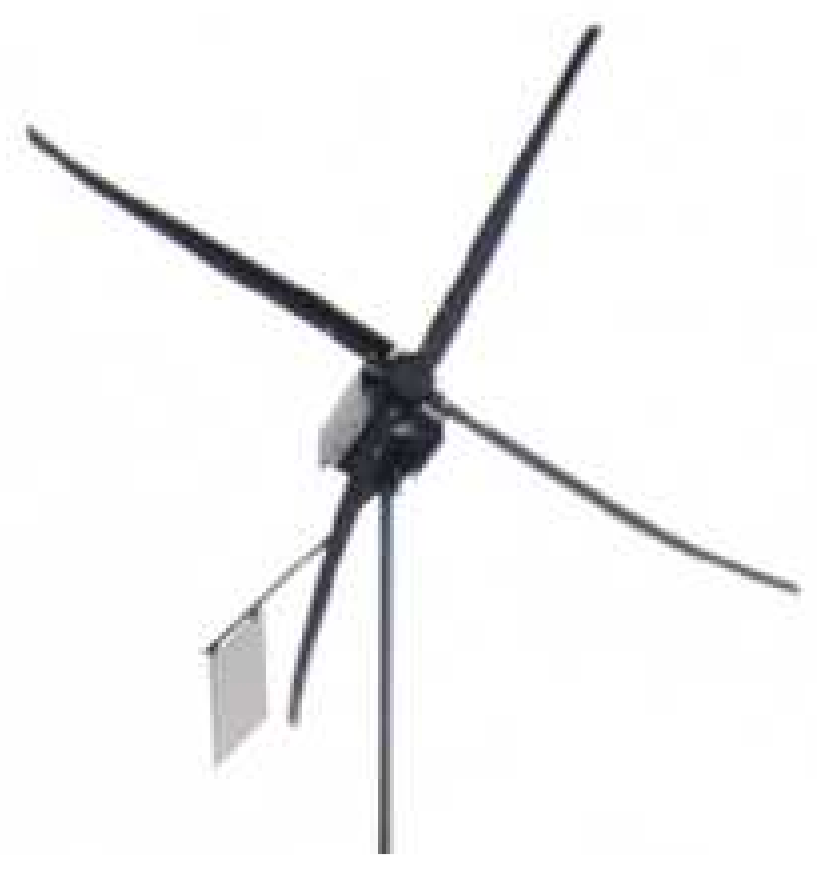

\title{
Low wind speed wind turbine in DIY version
}

Prof. Alex Van den Bossche

Ghent University, Electrical Energy Lab

Sint -Pietersnieuwstraat 41 Gent Belgium

\section{EVER 13}

\section{Monaco 27-30 March 2013}

Eighth International Conference \& Exhibition on ecological and renewable Energies
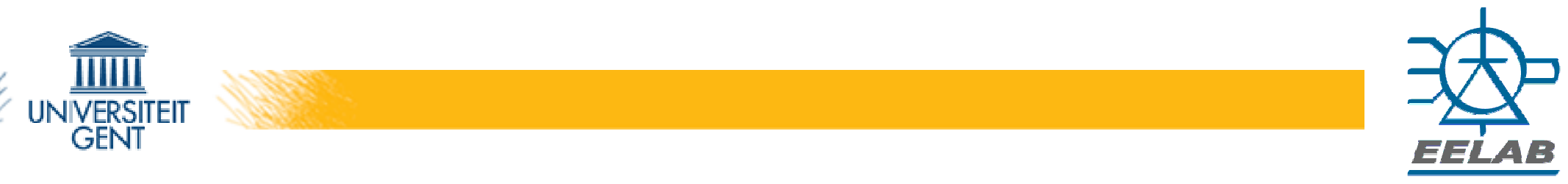


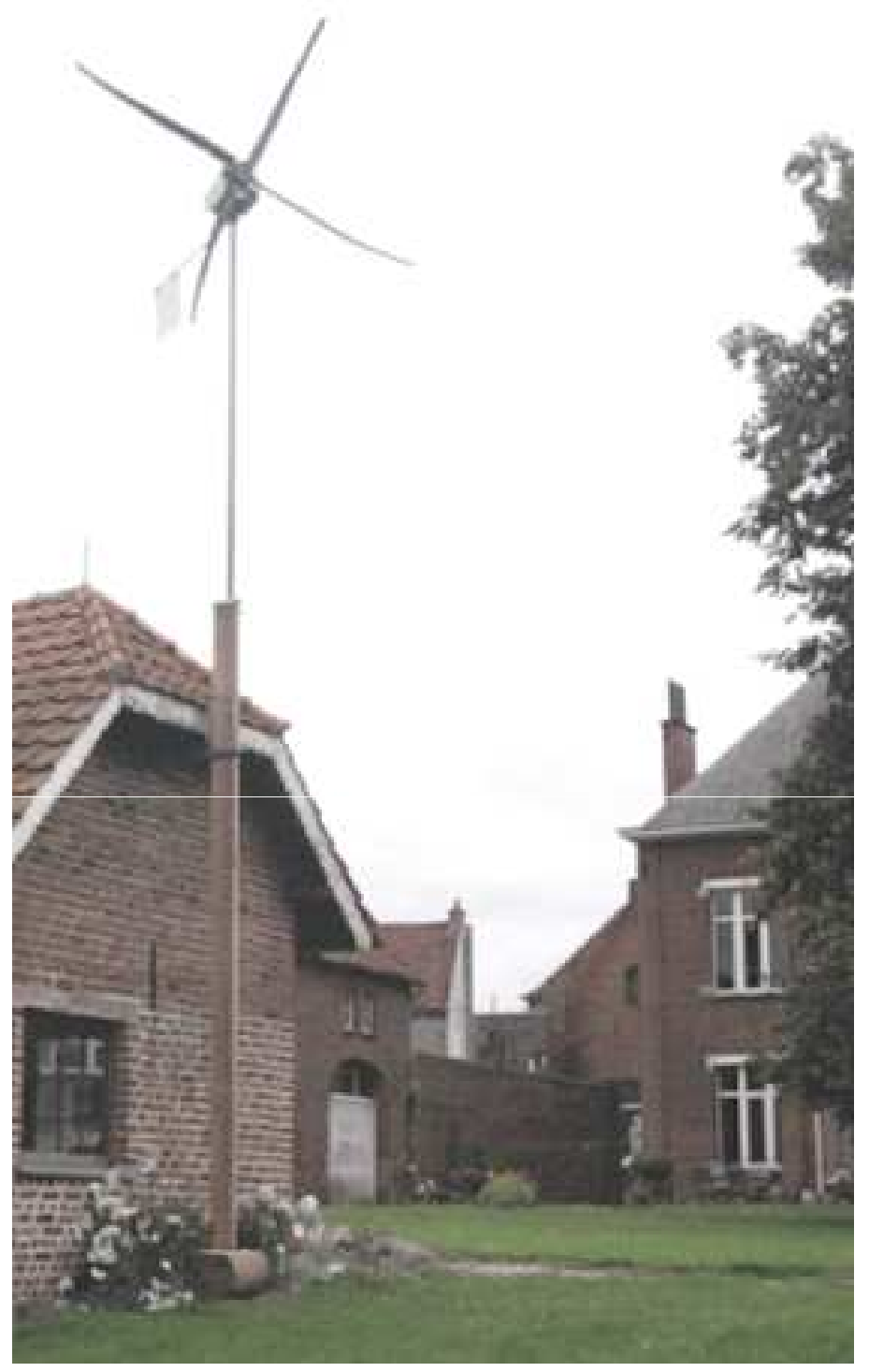

Fig. 1.

Wind turbine close to a small atelier
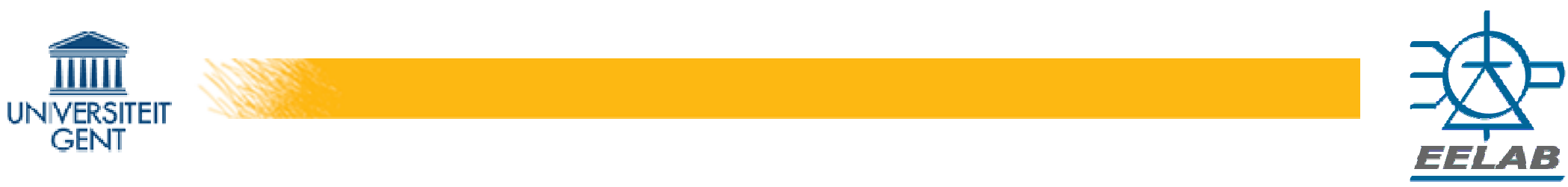


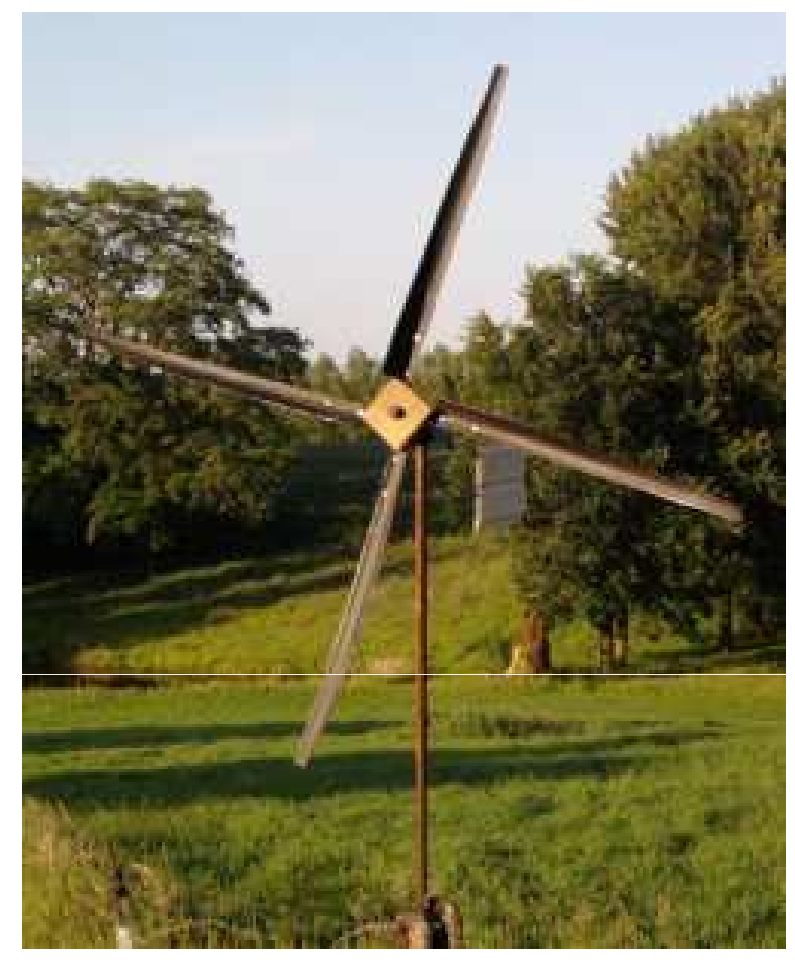

Fig. 2.

Earlier test of a small PE type without generator, $1.6 \mathrm{~m}$ diameter, from a $80 \mathrm{~mm}$ tube .

- Resists even only with furling tail, without brake or generator

- Does not resist with PVC tubes

- A 30 years old PE tube resists now in 3 years in site
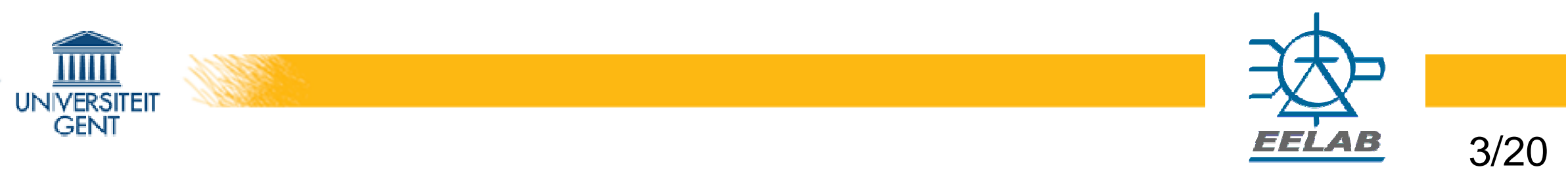


\section{Fig. 3.}

Top of foil with reference line for the angle .

Fig. 4.

Different angles with lift and drag components .
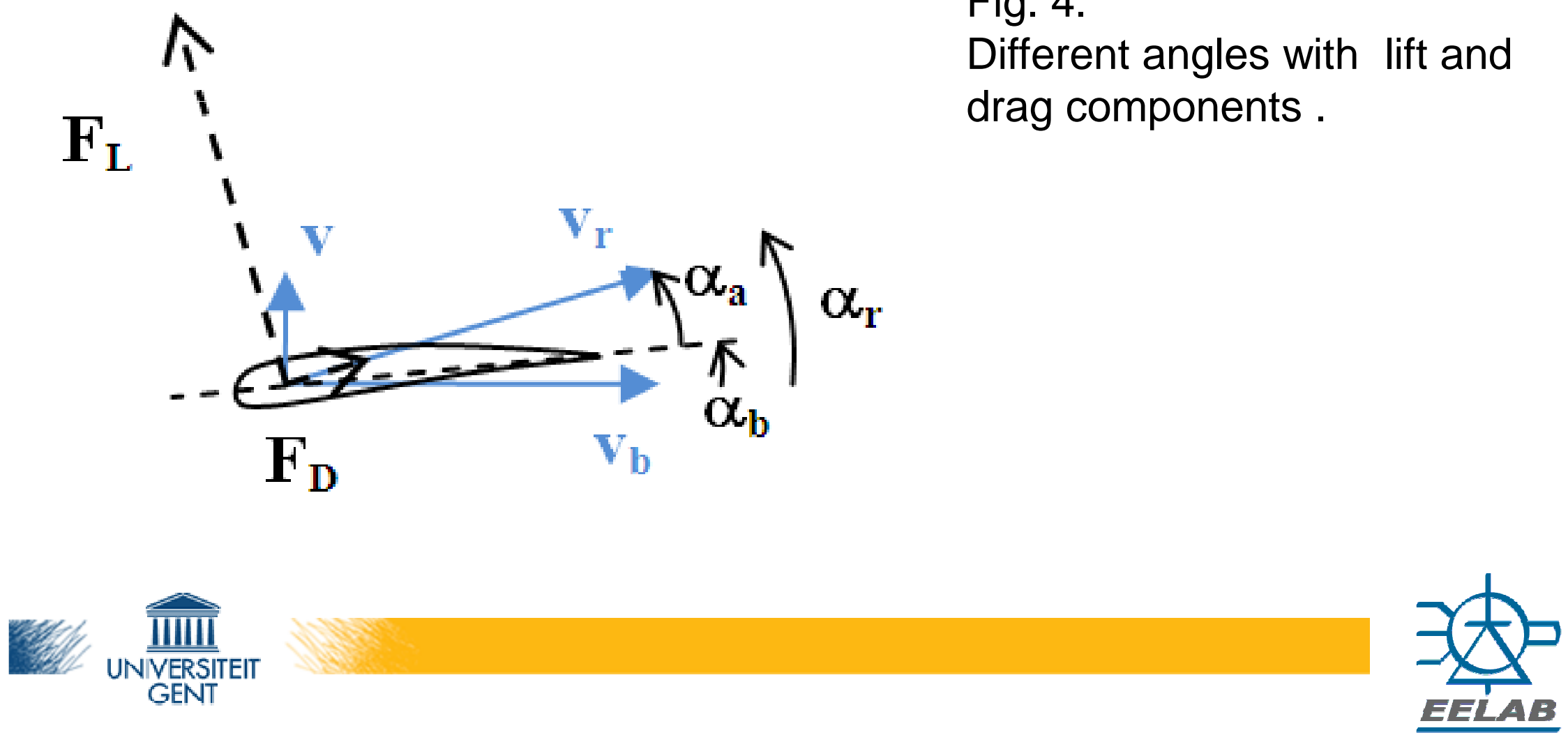
TABLE I DATA OF THE AIR FOILS

\begin{tabular}{|l|l|l|}
\hline type & $\begin{array}{l}\text { NACA } \\
9412\end{array}$ & Cut PE tube \\
\hline camber & $9 \%$ & $10 \%$ \\
\hline Max height at & $40 \%$ & $36 \%$ \\
\hline Max lift at & $12^{\circ}$ & \\
\hline Zero lift & $-9.5^{\circ}$ & $9^{\circ *}$ \\
\hline Stall angle & $12^{\circ}$ & \\
\hline thickness & $12 \%$ & $12.6 \%$ \\
\hline Max L/D & 58.12 & $58.12 / 1.2^{*}$ \\
\hline Max L/D angle & $0.5^{\circ}$ & $58.12 / 1.2^{*}$ \\
\hline Max $C_{\mathrm{L}}$ angle & $14.5^{\circ}$ & \\
\hline Max $\mathrm{C}_{\mathrm{L}}$ & 2.148 & $2.1^{*}$ \\
\hline \multicolumn{3}{|l|}{ *: estimated } \\
\hline
\end{tabular}

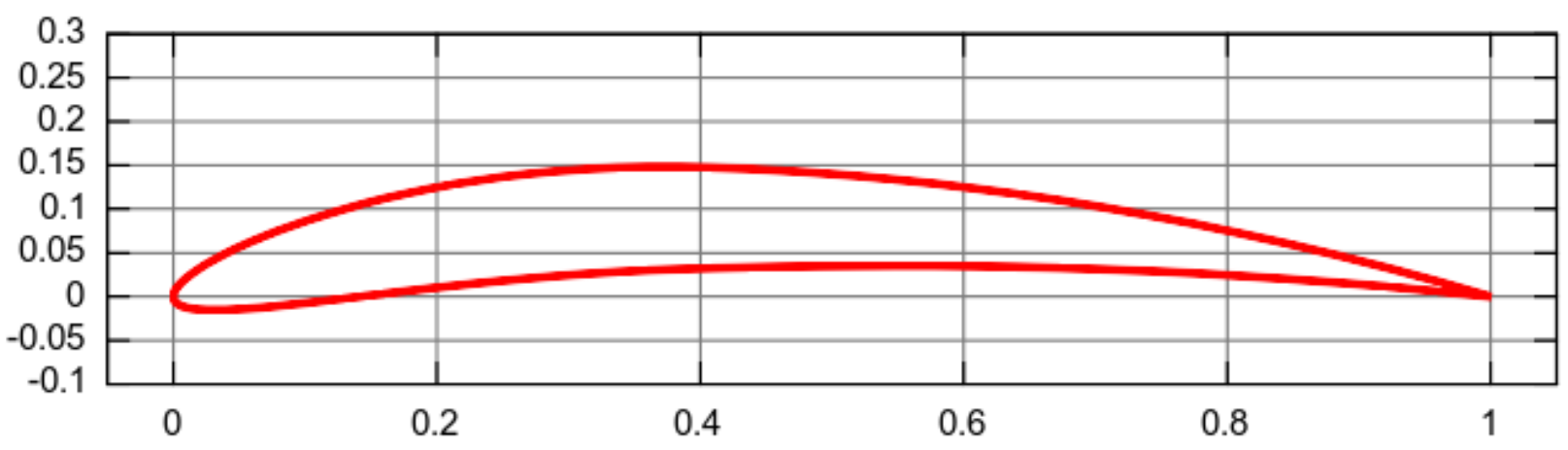

Fig 5.

NACA9412 air foil
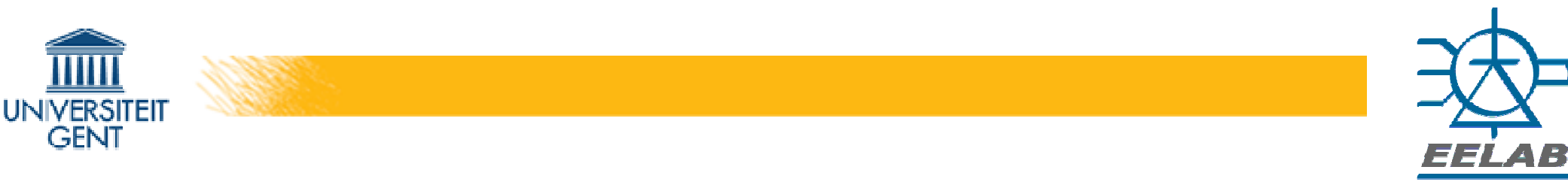


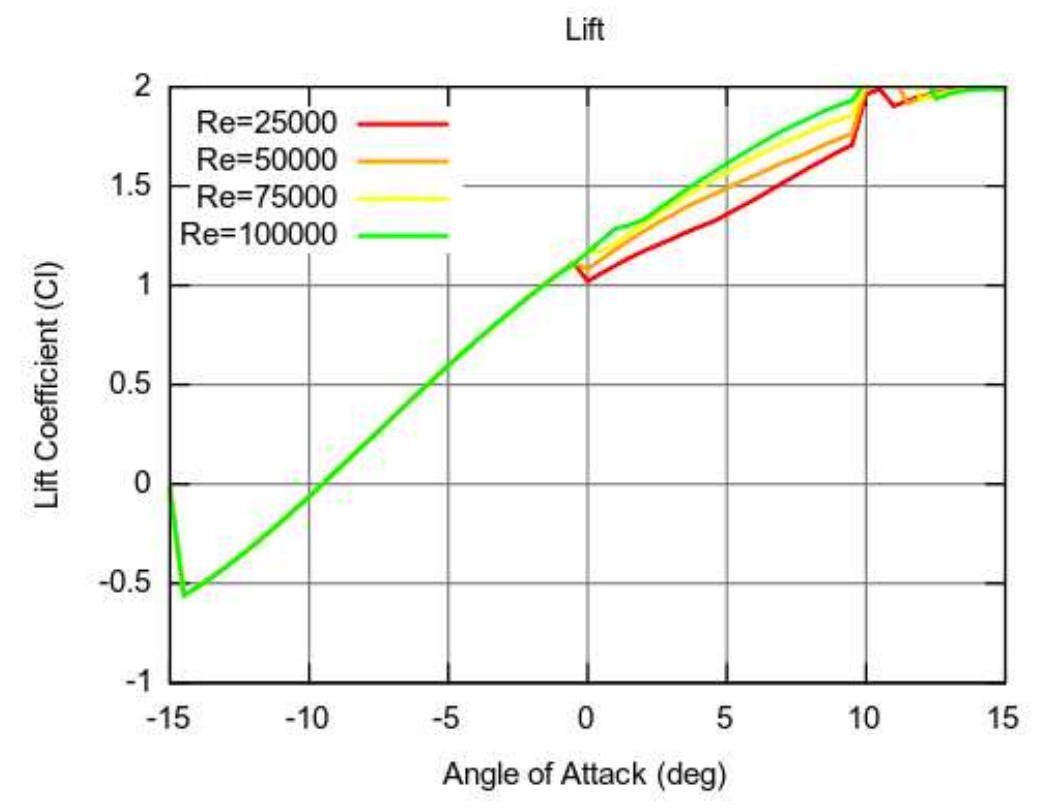

Polar

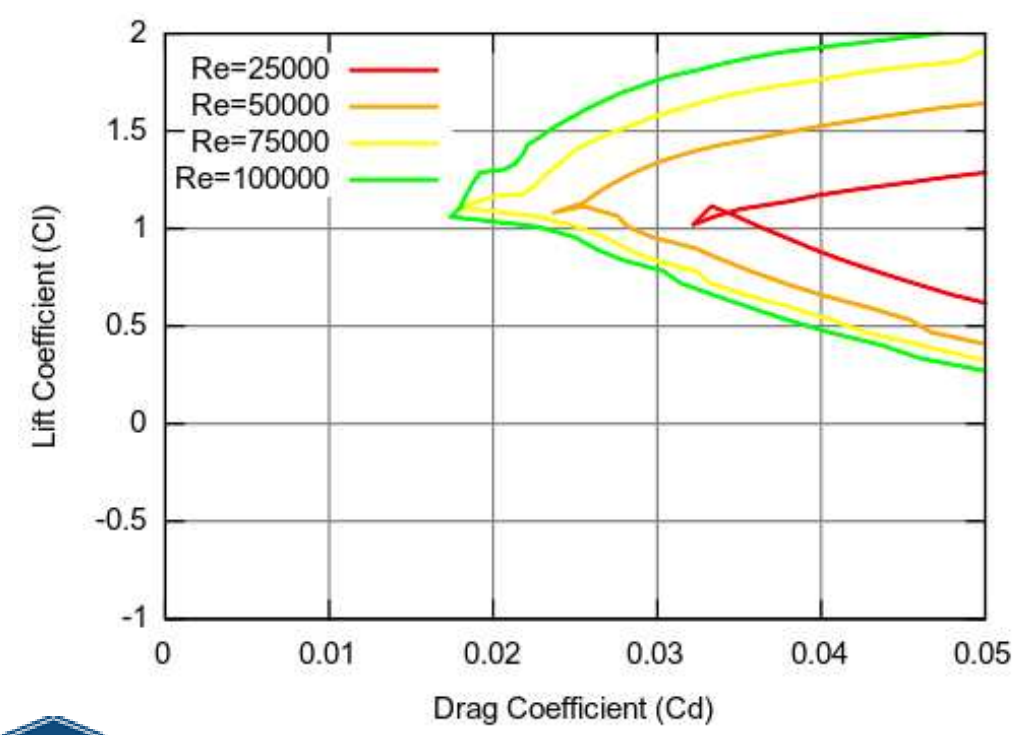

Fig 6.

CL depending on the angle of attack

(NACA9412 air foil)
Fig 7. CD depending on $\mathrm{CL}$ (NACA9412 air foil)

- Good maximum lift/drag - Bad drag at low lift

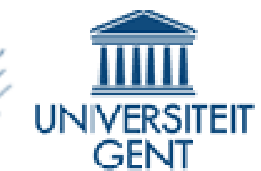




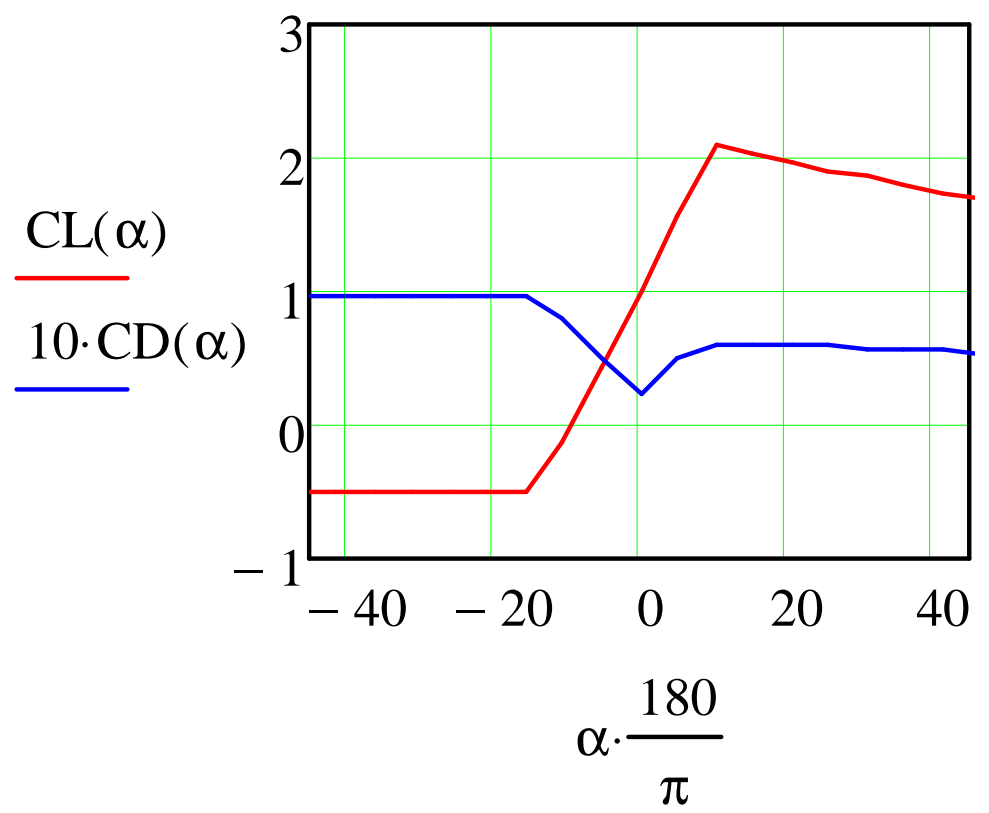

Fig. 8 Modeled lift and drag depending on the angle of attack

$\frac{F_{a}}{\Delta r}=\frac{1}{2} \rho w b\left(v_{r}^{2}\right)\left(\sin \left(\alpha_{r}\right) C_{L}-\cos \left(\alpha_{r}\right) C_{D}\right)$

(10) Force from air foil $v_{r}$ is tangential speed of the foil

$$
F=\frac{1}{2} \rho S\left(v_{1}^{2}-\left(2 v_{1}-v\right)^{2}\right)
$$

(6) Force from Betz theory

$\mathrm{v}=$ local at turbine

v1: undisturbed wind
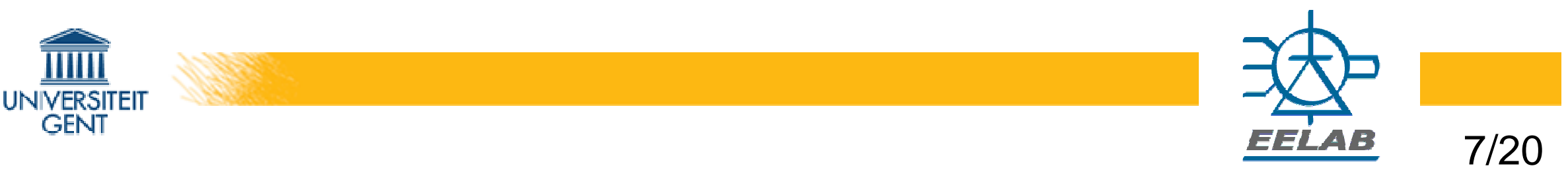


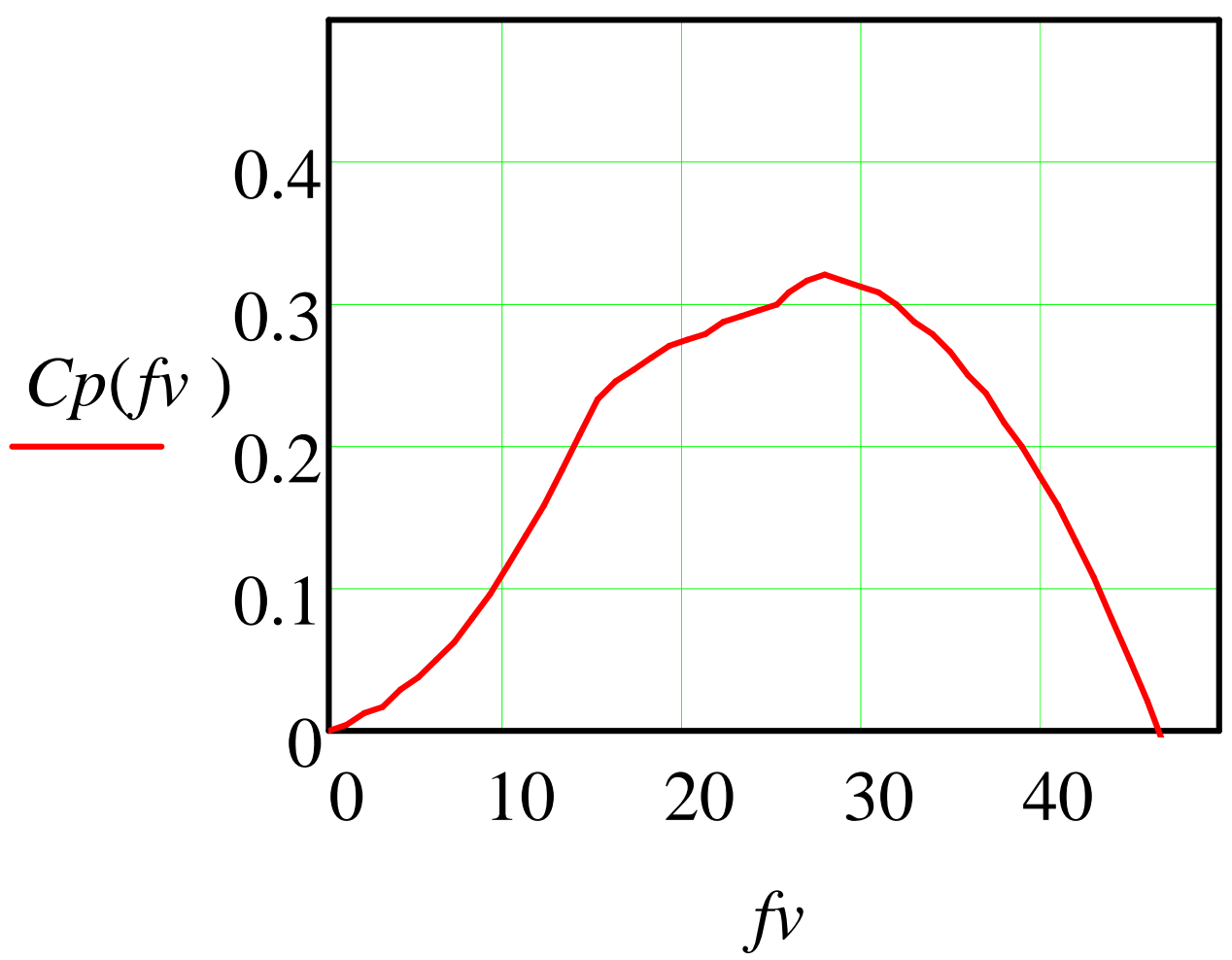

Fig. 9 Power coefficient versus frequency of the turbine at $7 \mathrm{~m} / \mathrm{s}$ wind speed

- Equalizing the both ways of force calculation permits to estimate the frequency - power coefficient curve
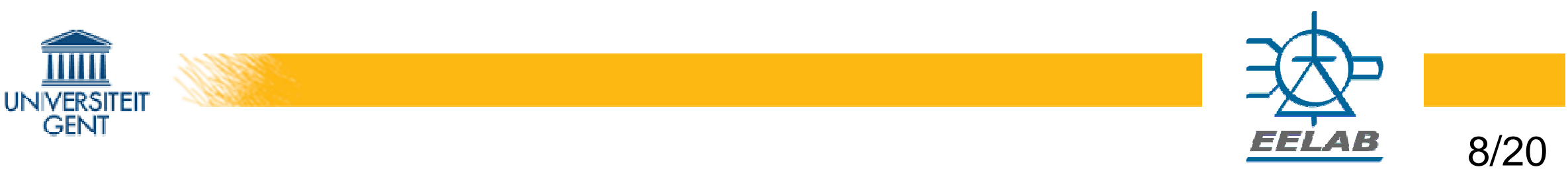


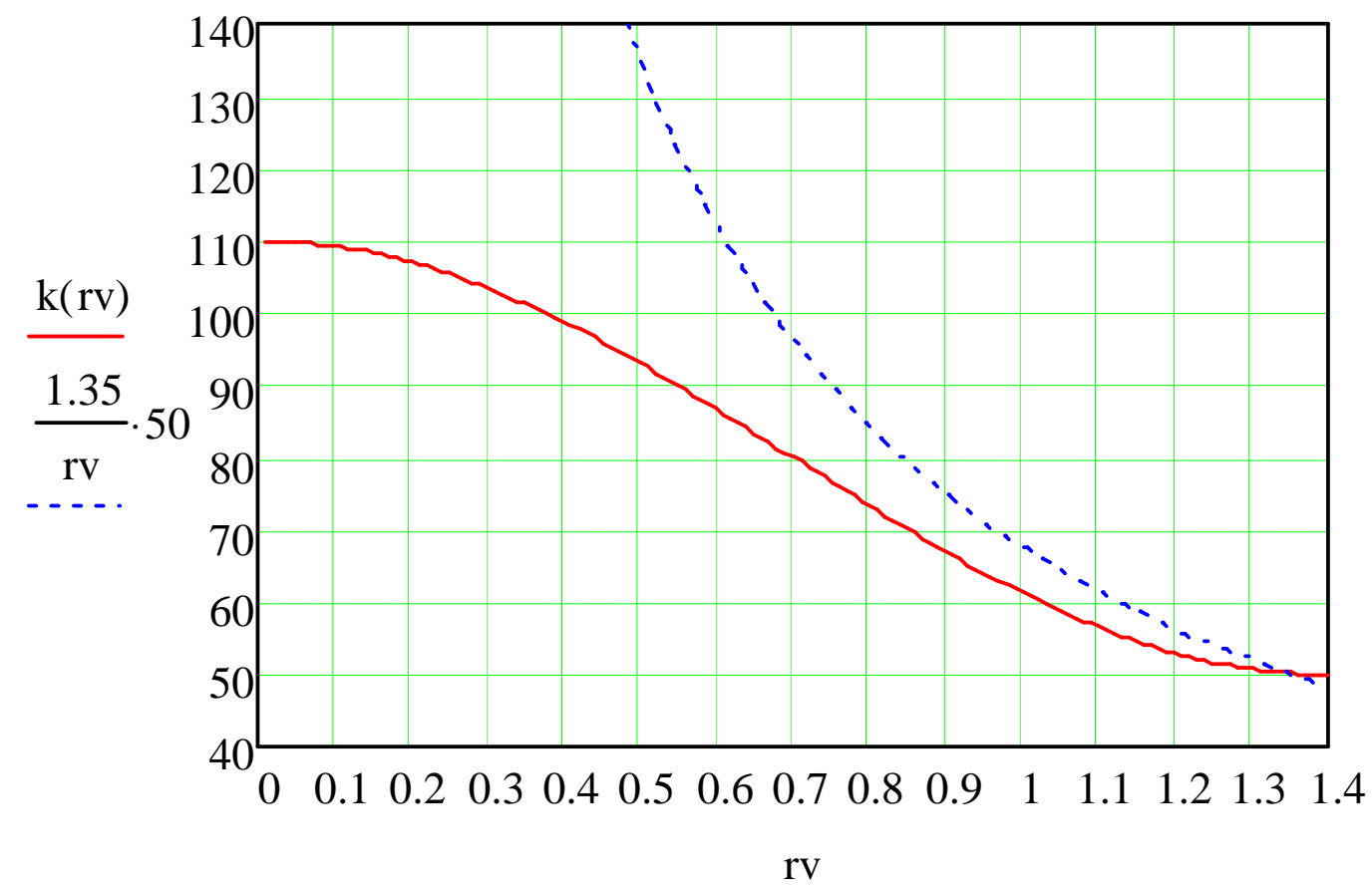

- Realised blade chord profile depending on radius A compromise between strenght and ideal width
Fig. 9

Full line, the realized chord $k(r v)[\mathrm{mm}]$, depending on the distance from the axis. A hyperbola is added in dotted line.

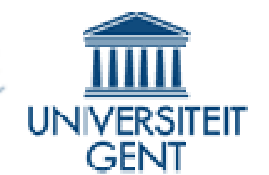




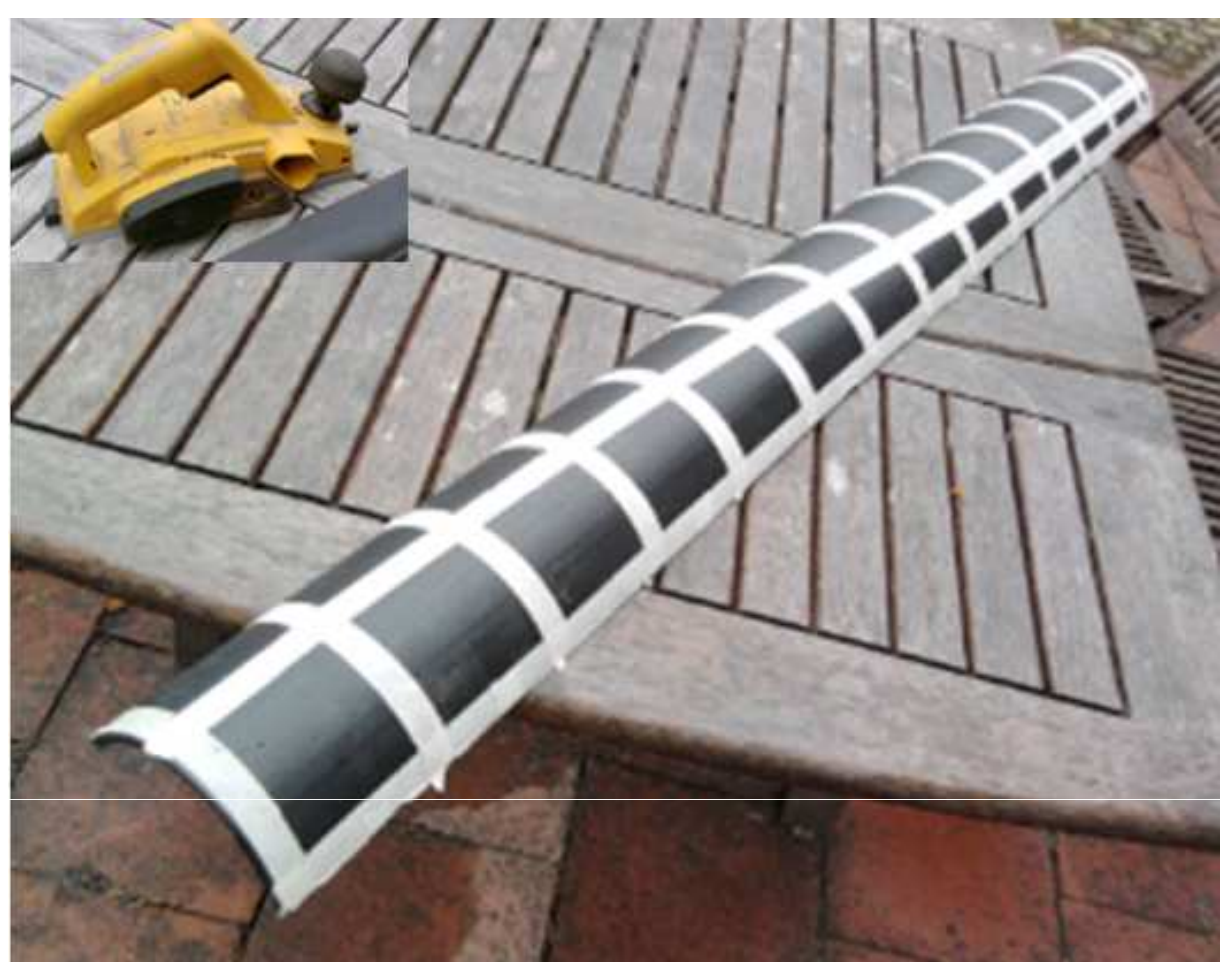

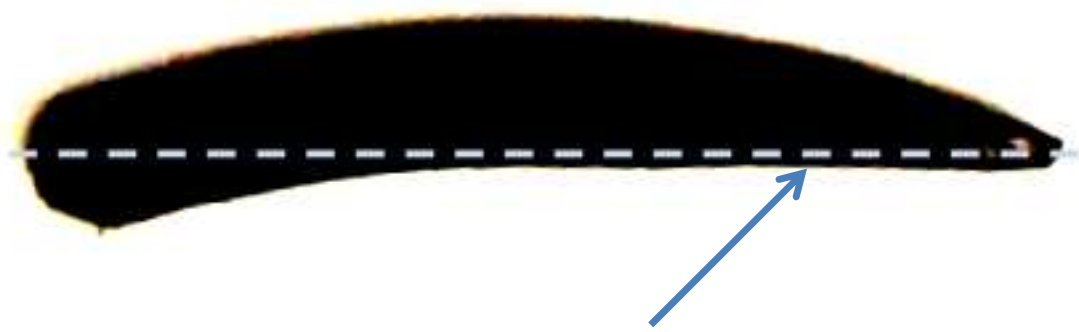

Planed surface
Fig 13.

A piece of PE tube for two blades, one curve is marked; upper left: planning machine.

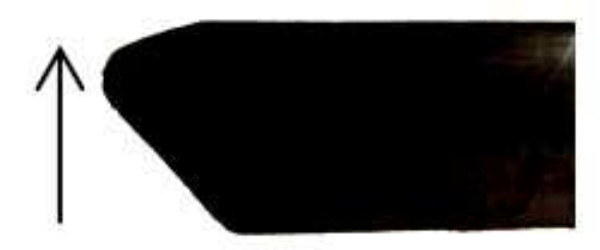

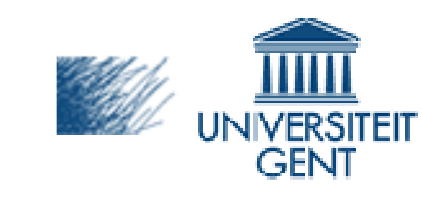

Fig 14.

Tip of the blade finishing and the direction of movement
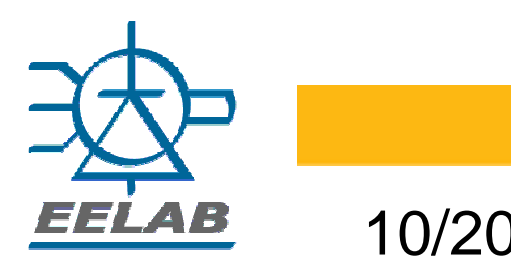


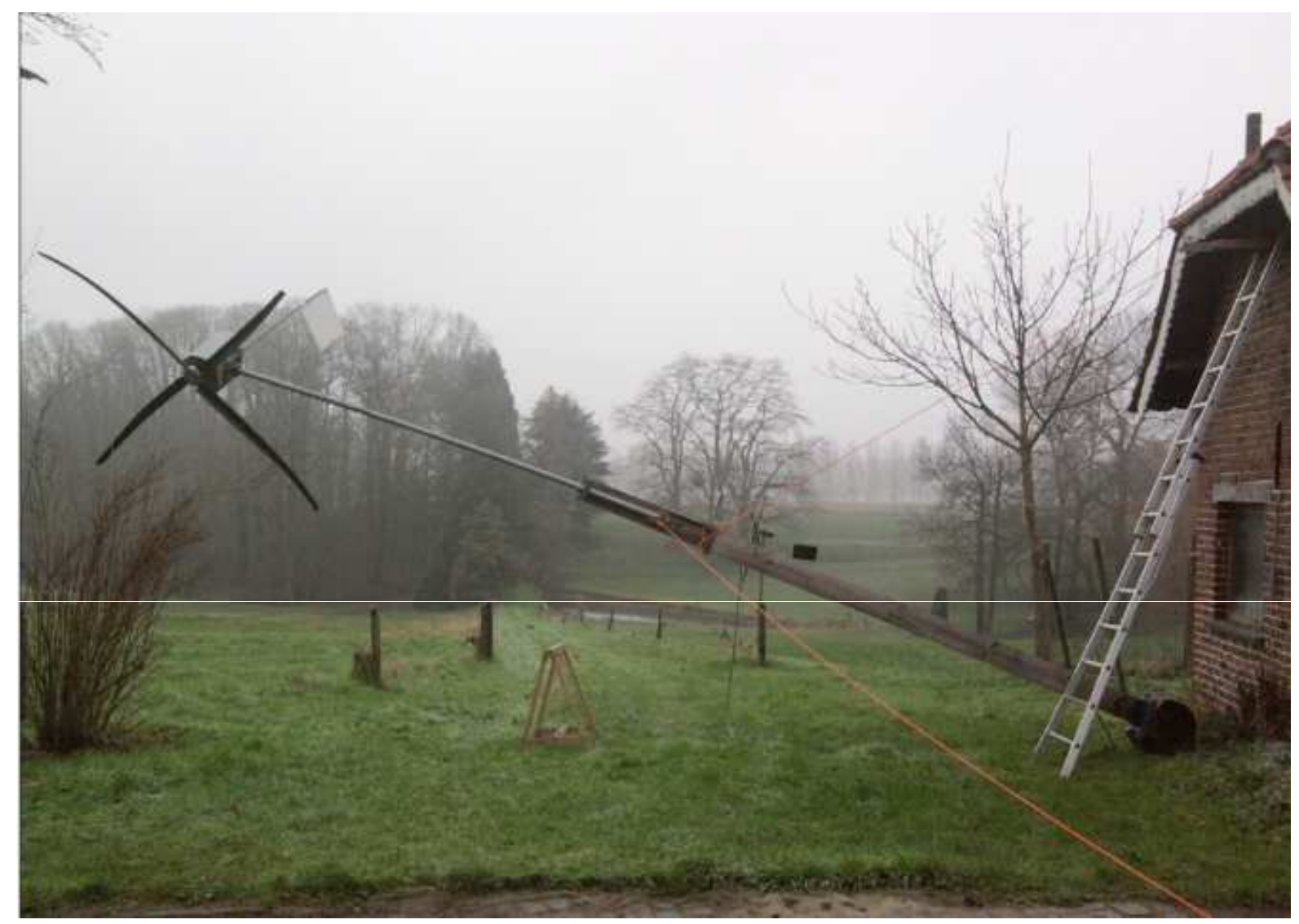

Fig 15.

Erecting the turbine, showing the effect of the own weight of the nacelle.

Windlass inside the building, pulls up.

The link is to the roof, not to the wall

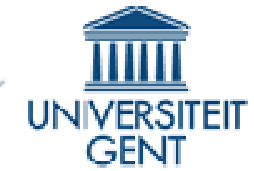




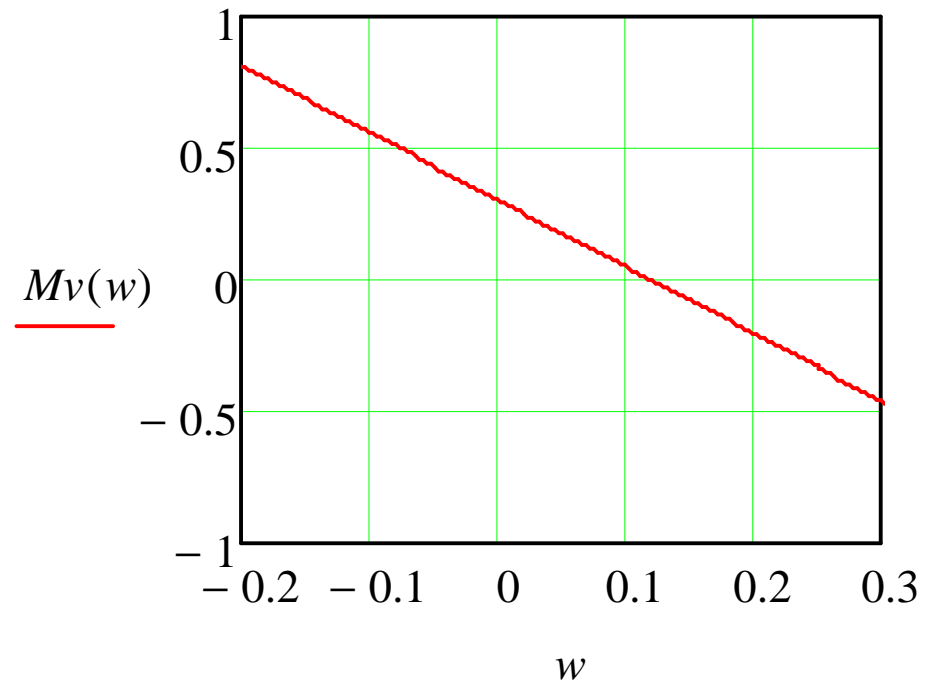

Fig 13.

Parasitic moment around the vertical axis, vertical [Nm] horizontal relative tilt []. 


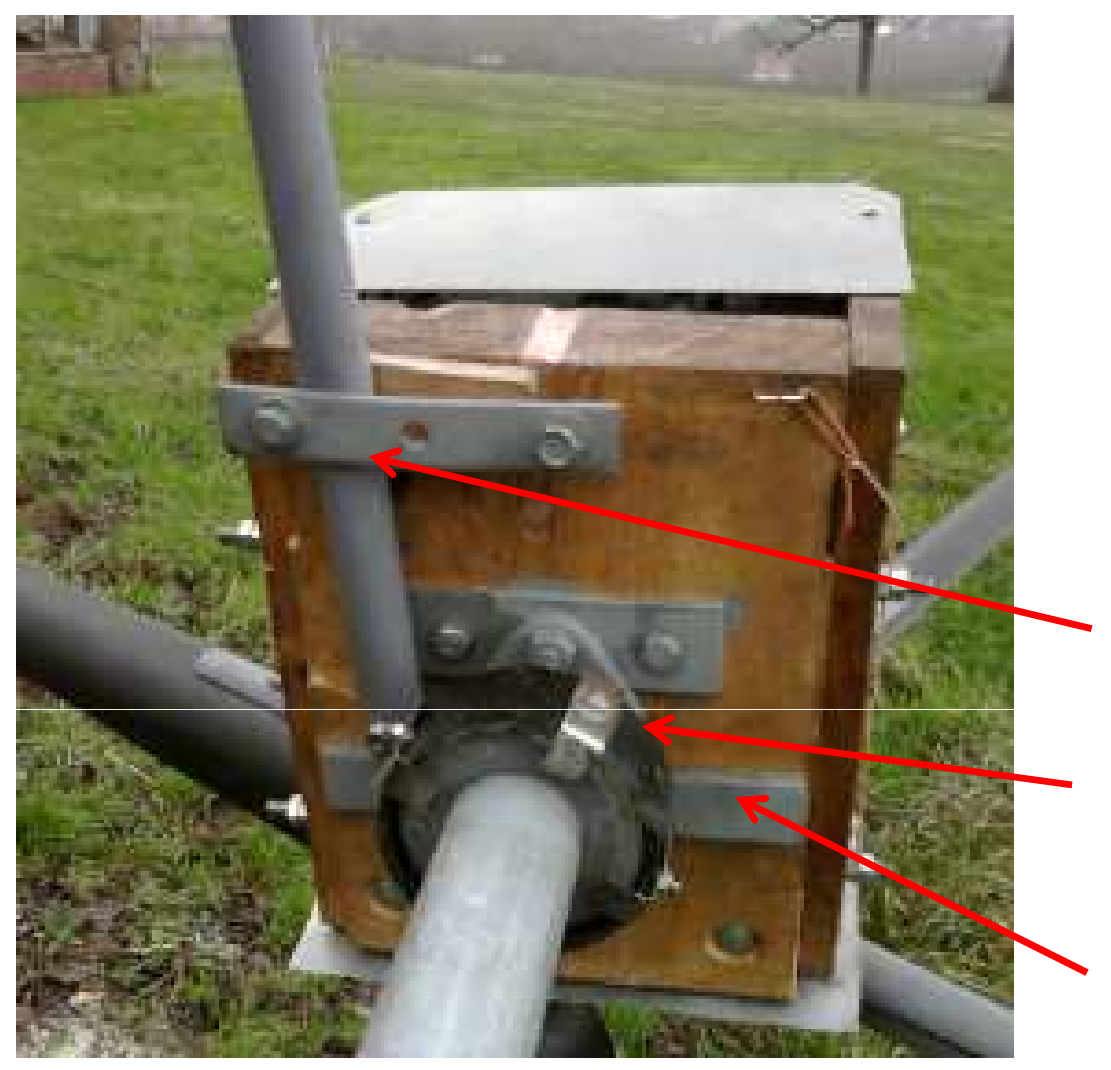

Fig 12. Bottom view of the nacelle, axis, bearing(black), skewed tail.

\section{Tail skew}

"Hybrid" vertical thrust bearing using marbles (black)

Tilt spacer

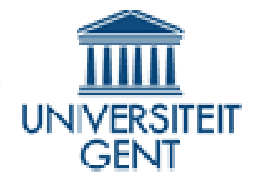




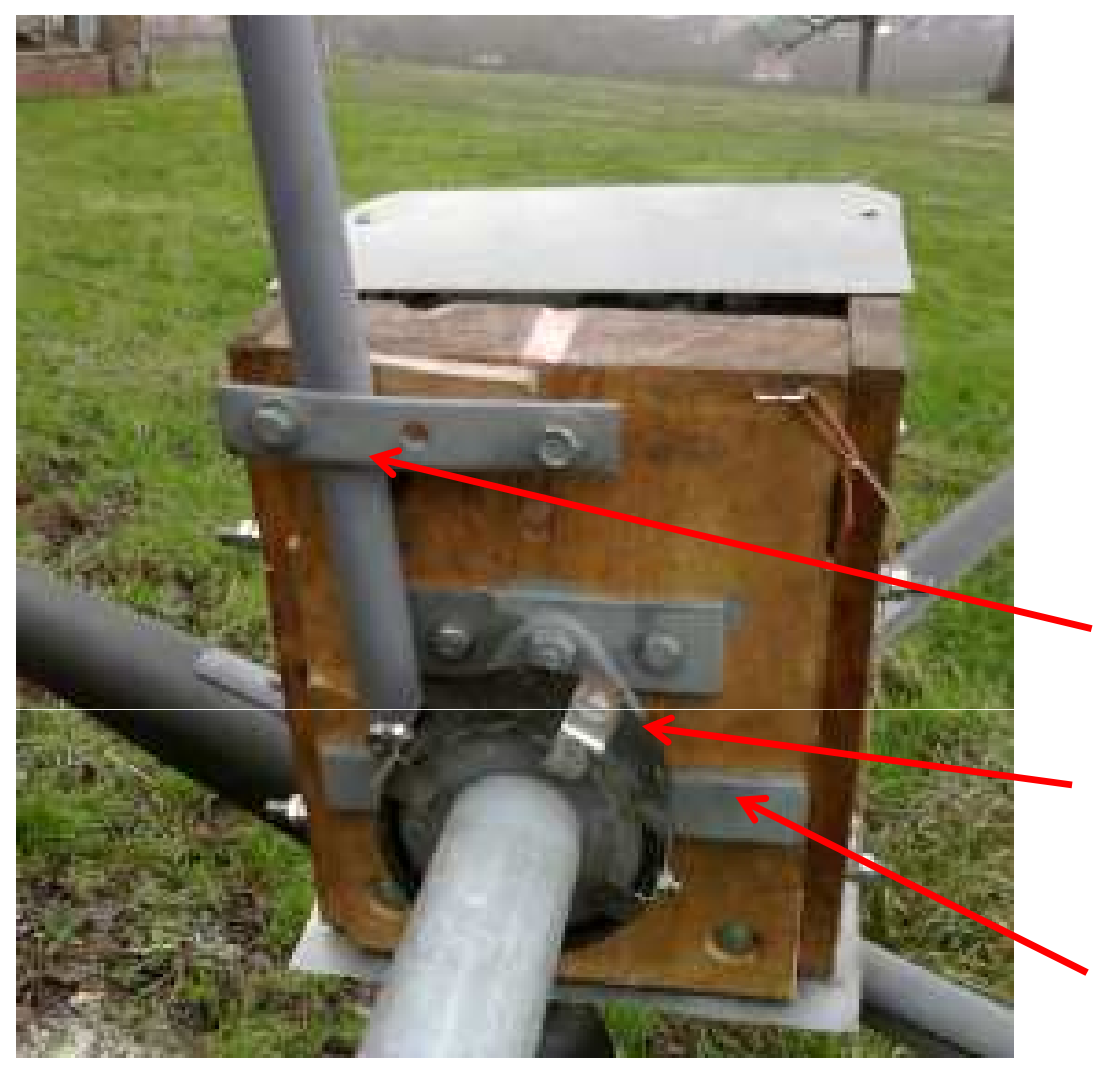

Fig 12. Bottom view of the nacelle, axis, bearing(black), skewed tail.

\section{Tail skew}

"Hybrid" vertical thrust bearing using marbles (black)

Tilt spacer
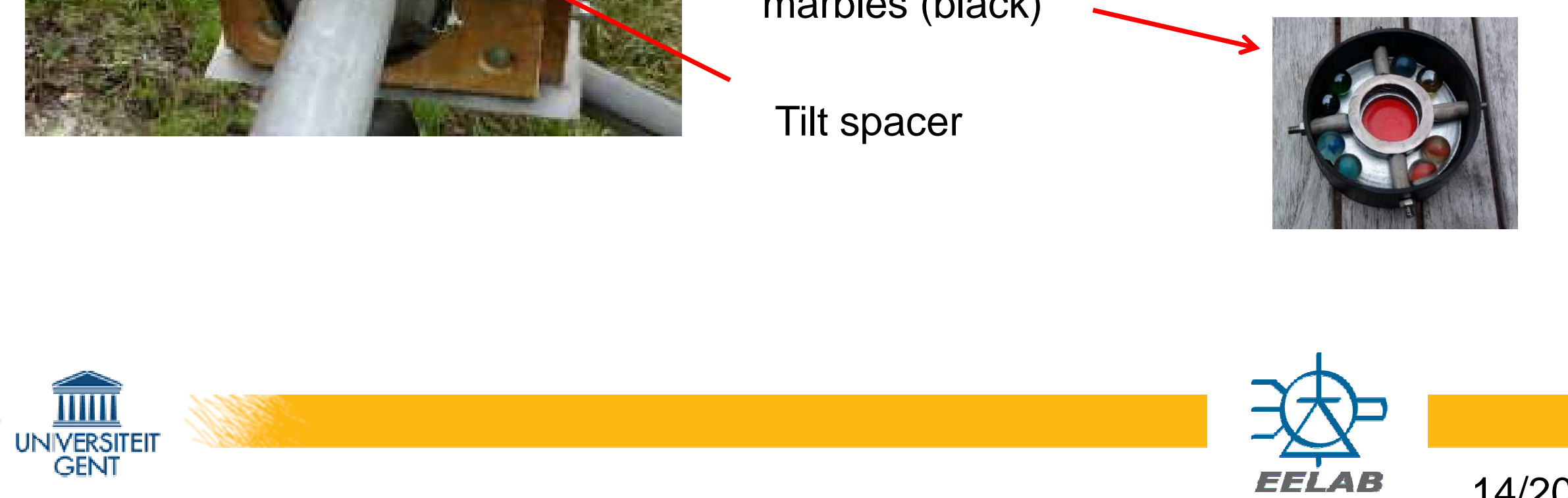


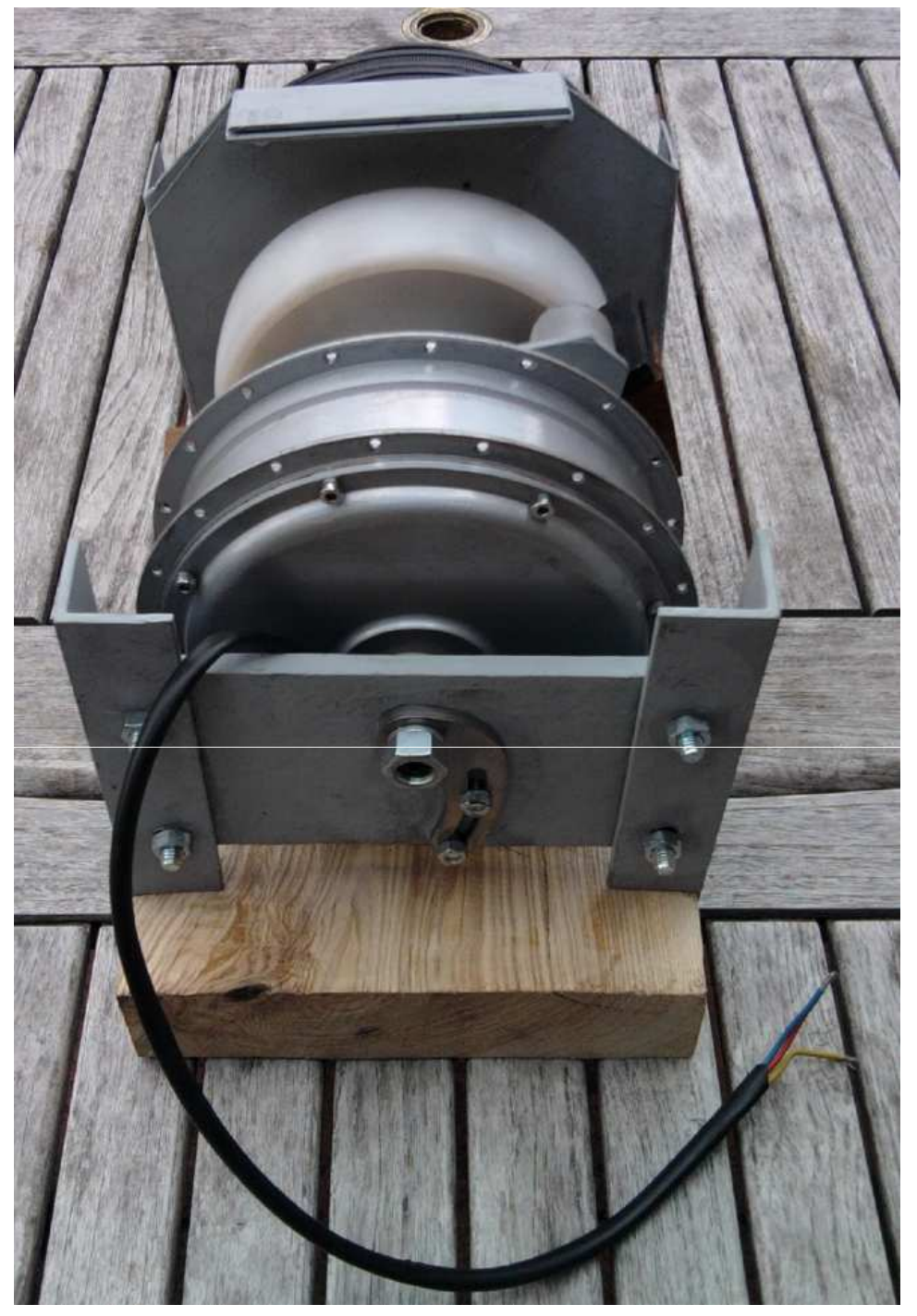

Electric bike motor as Generator and additional bearing
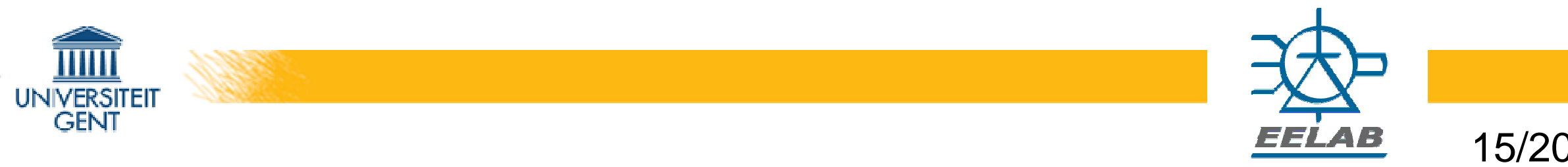


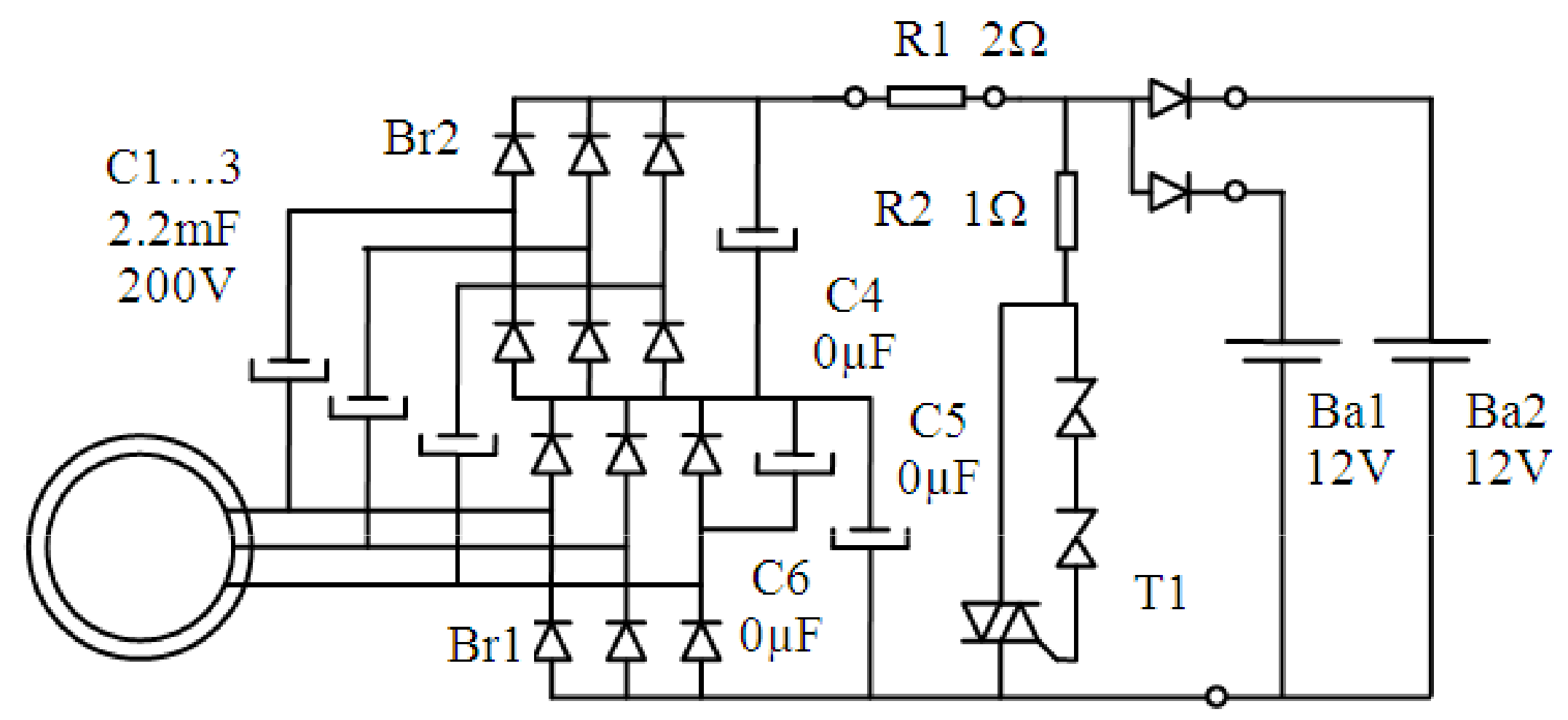

Fig. 17 Passive converter with three-phase voltage doubler (or quadrupler if C4-C5-C6 are non-zero) 


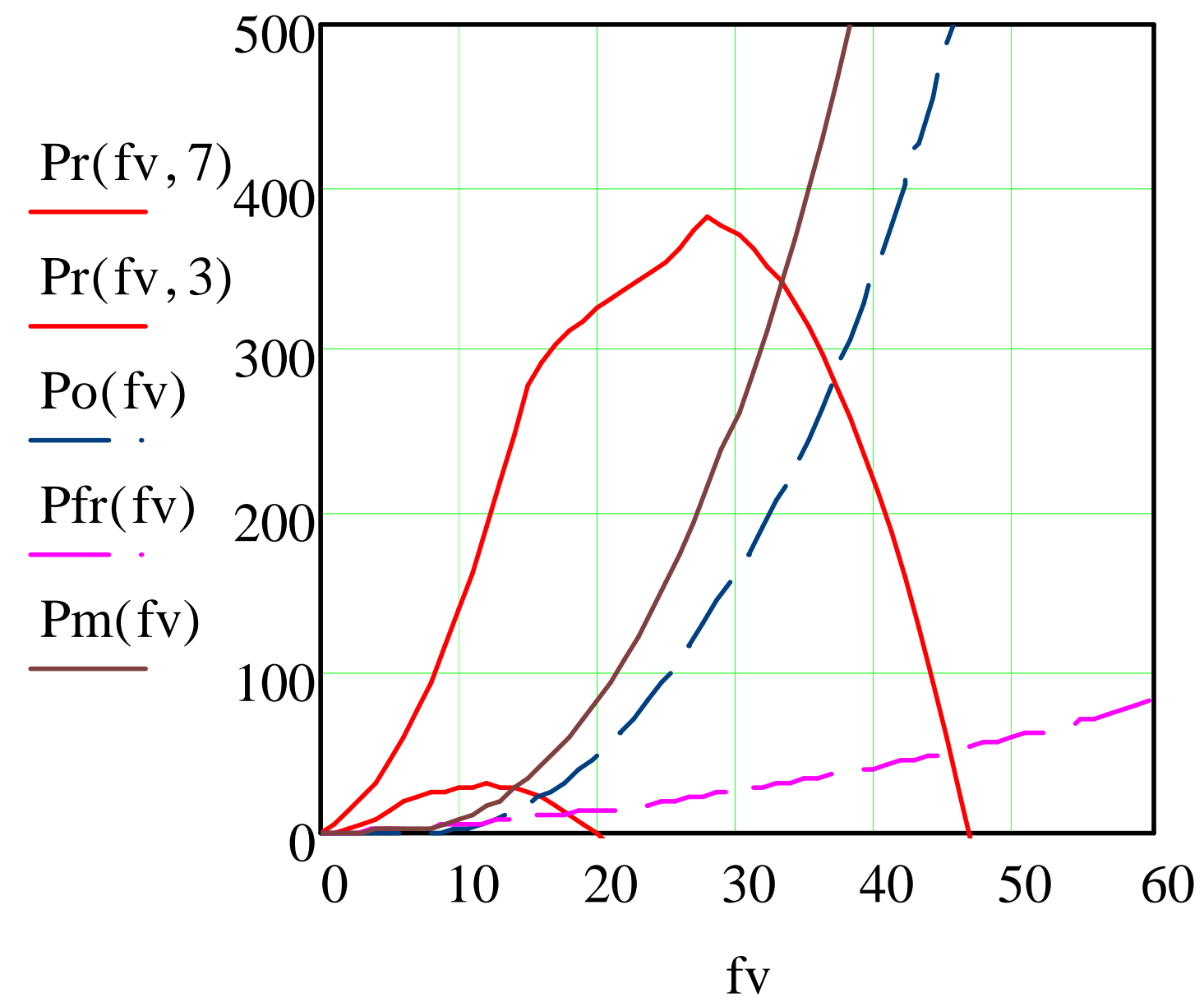

Close-up at low wind speed, taking friction into account
Fig. 19. Load and absorbed power and turbine characteristic for $\mathrm{v} 1=3 \mathrm{~m} / \mathrm{s}$ and $2 \mathrm{~m} / \mathrm{s}$
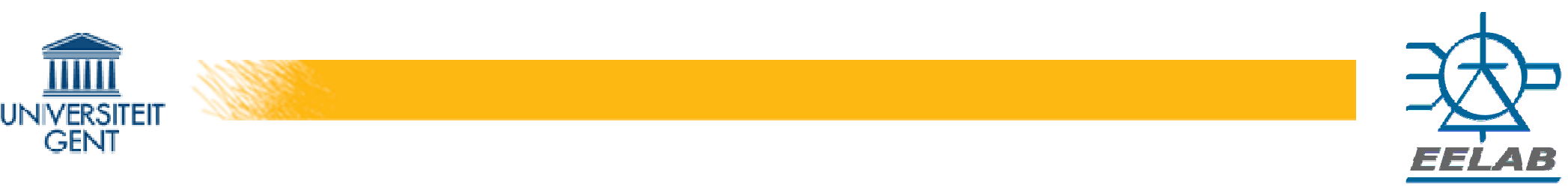


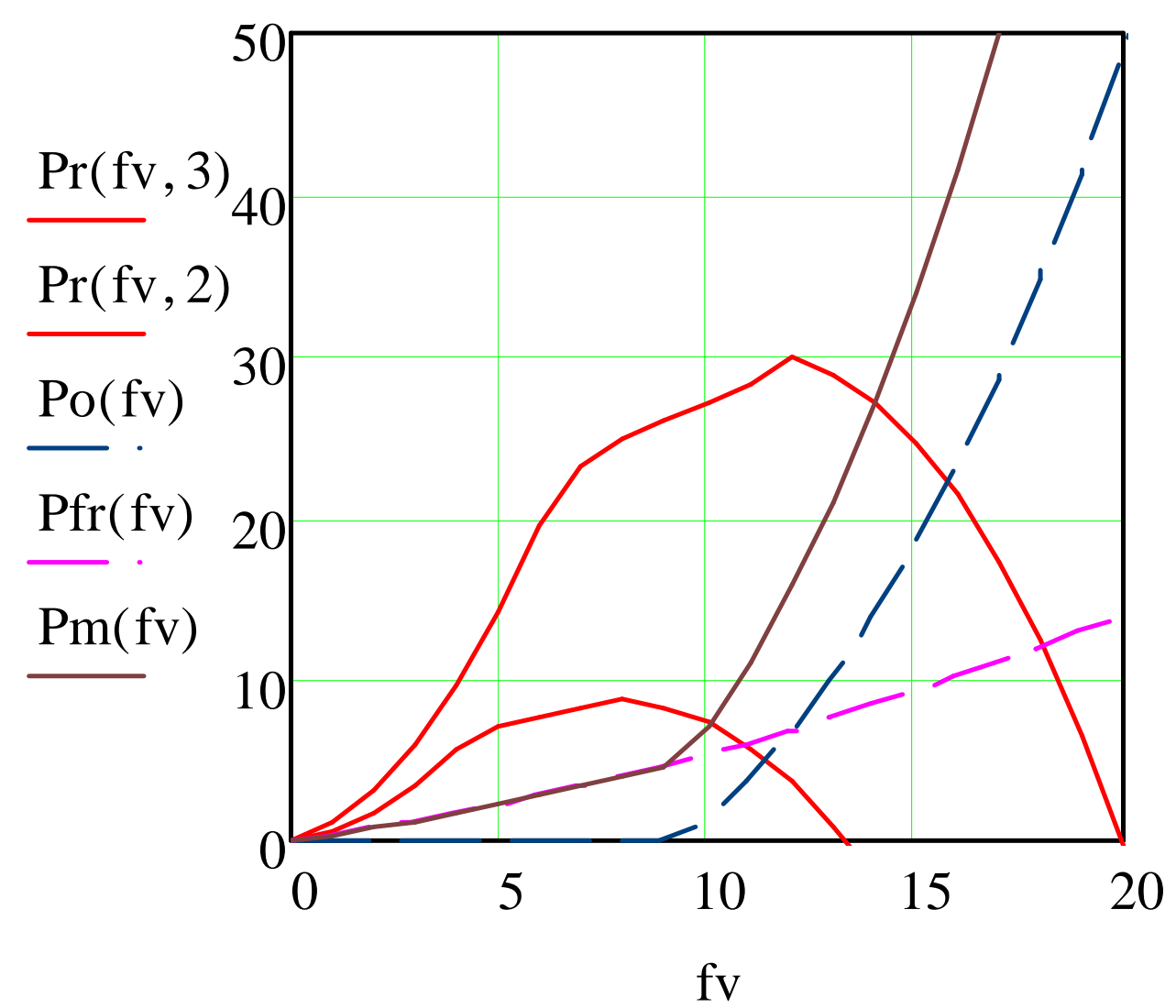

Close-up at low wind speed, taking friction into account
Fig. 19. Load and absorbed power and turbine characteristic for $\mathrm{v} 1=3 \mathrm{~m} / \mathrm{s}$ and $2 \mathrm{~m} / \mathrm{s}$

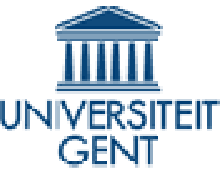



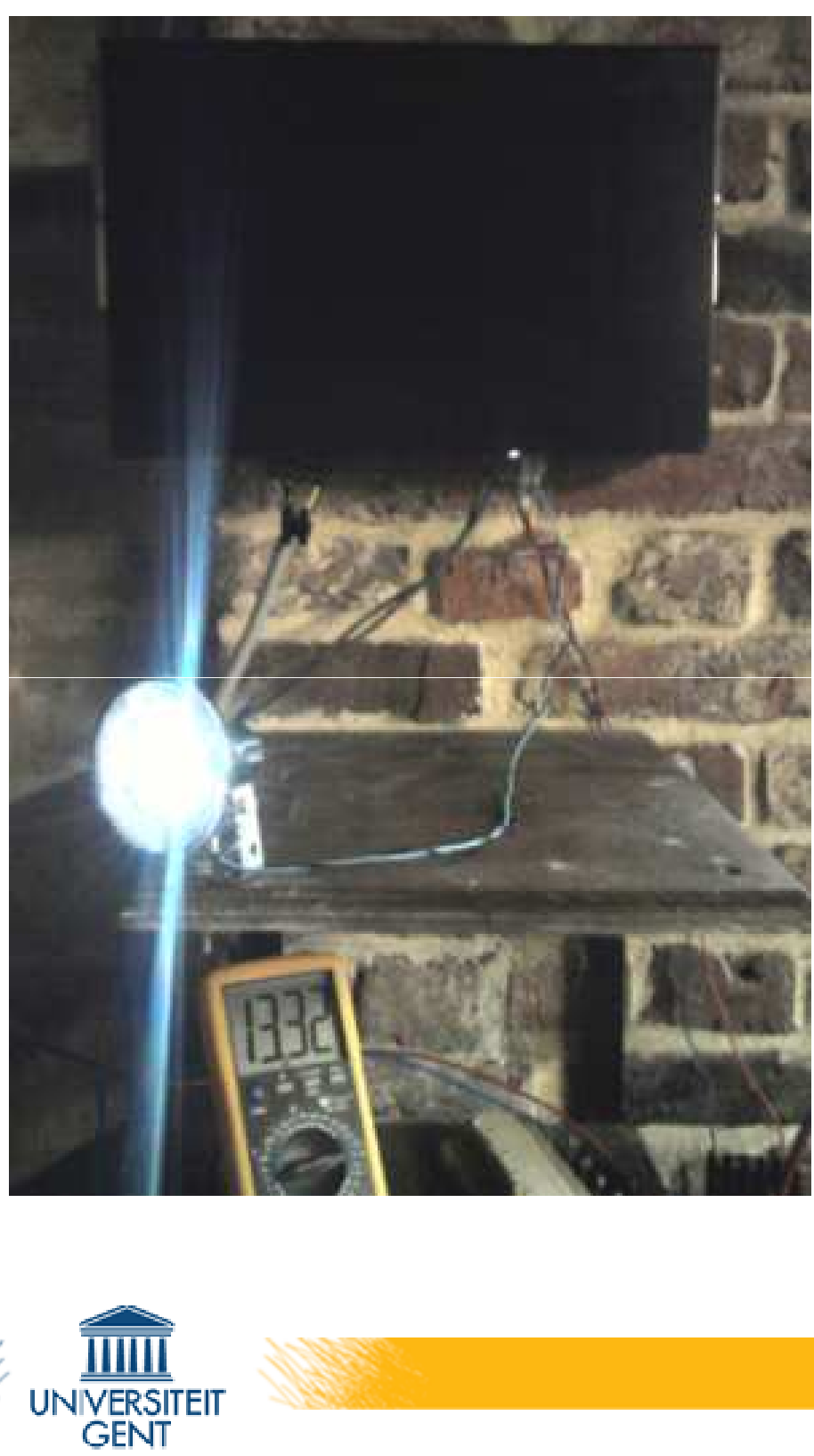

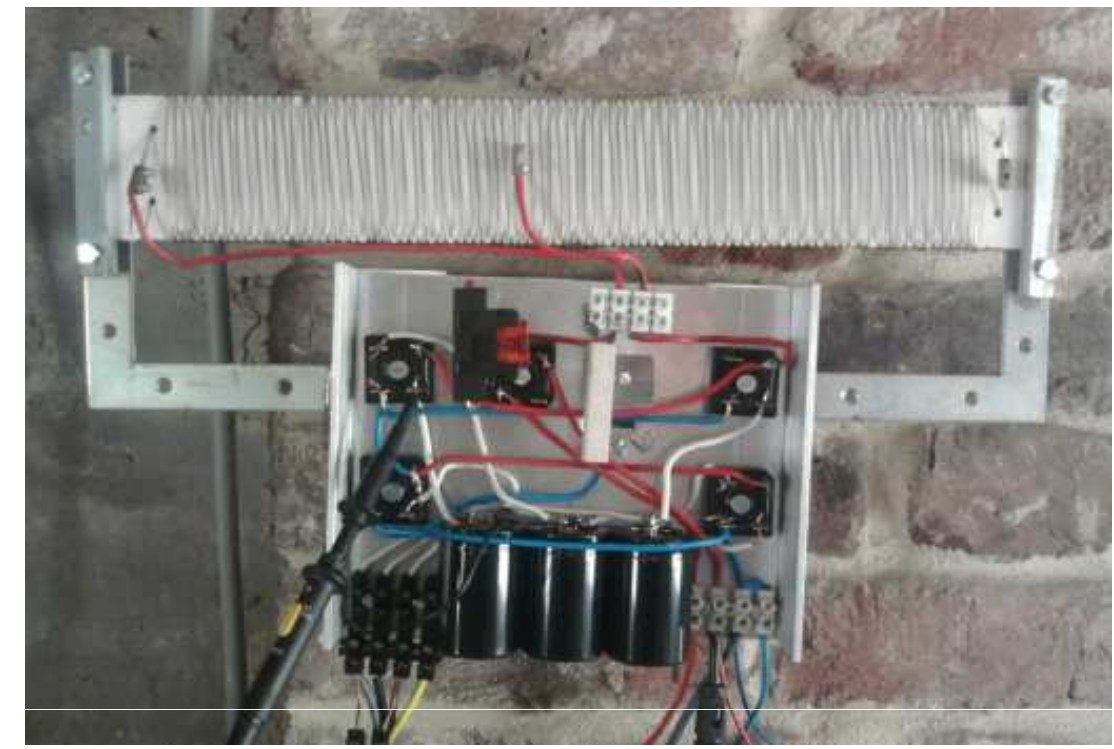

Fig. 20 Resistor Load and Rectifier and resistor closed and open.

A $1 \mathrm{kWh}$ battery charges in 8 days in winter.
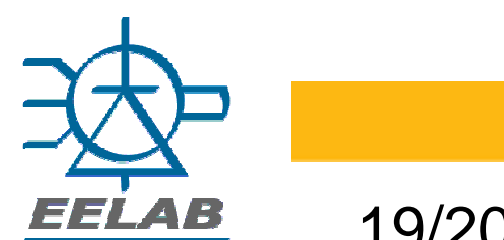


\section{Low Wind speed Wind Turbine in DIY}

\section{Conclusion:}

$\checkmark$ A low BOM (350 euro) is possible using

- a bike PM generator

- PE blades

- Simplified tower

$\checkmark$ One needs a voltage multiplier to use well a bike generator on $12 \mathrm{~V}$ battery at low wind speed.

$\checkmark$ PE blades resist well to harsh conditions

$\checkmark$ Inland small wind turbines are still not very cheap compared to solar

$\checkmark$ Wind turbines generate more electricity in winter. 